\title{
omunicação Visual e Acessibilidade do Turista Estrangeiro na Cidade de São Paulo
}

Flávia Ulian ${ }^{1}$
Laura Vigia Dias

RESUMO: Apresenta pesquisa sobre sinalização verbal e não verbal (visual) disponível para o turista estrangeiro, de diversas regiỏes do mundo, em seus deslocamentos no município de São Paulo e contribui para a discussão do planejamento turístico municipal no País. Foram utilizados registros fotográficos, bem como o levantamento e análise de depoimentos de turistas estrangeiros em São Paulo e de documentos fornecidos pelas entidades responsáveis por esse tipo de atendimento ao turista para embasar a análise qualitativa de como esses recursos de linguagem viabilizam e/ou dificultam a comunicação e a mobilidade do turista estrangeiro na cidade.

PALAVRAS-CHAVE: comunicação no turismo, comunicação visual, mobilidade e acessibilidade, sinalização turística, planejamento turístico, turismo receptivo, São Paulo (cidade), Brasil.

ABSTRACT: This article presents datafrom a research on verbal and non verbal (visual) aids available for the foreign tourist who comes from several regions over the world in his moves in the city of São Paulo and at contributing for the cities tourist planning discussion in Brazil. There were photographic registers as well as the survey and the analysis of foreign tourists statements in São Paulo and also the analysis of documents given by the institutions which are responsible for such type of tourist

1. Mestre em Geografia Humana pela Universidade de São Paulo. Docente de Geografia Aplicada ao Turismo, Turismo Ambiental e transportes em cursos de Turismo.

End.: Rua Dr. Alvino Lima, 16 - 04103-040 - São Paulo - Brasil.

E-mail: fulian@bol.com.br

2. Mestre em Lingüística Aplicada pela Universidade de Campinas. Docente de Inglês Instrumental e de Metodologia

Científica em cursos de Turismo e de Comunicação.

End.: Rua A. J. Santos, 524 - 05661-020 - São Paulo - Brasil.

E-mail:indyanna@uol.com.br 
reception based on which, there was a qualitative analysis of how those language resources facilitate and/or become the foreign tourist communication and mobilization difficult in town.

KEYWORDS: tourism communication, visual communication, mobility, tourism signaling, tourism planning, receptive tourism, São Paulo (city), Brazil.

\section{Introduçāo}

A noção de turismo tem como elemento implícito a viagem ou deslocamento. De acordo com Beni (1998), "sem deslocamento não existe turismo". A temática deste trabalho, comunicação visual e acessibilidade, está estreitamente ligada a esse conceito fundamental na investigação científica no campo do Turismo.

São Paulo, a cidade mais visitada por estrangeiros no país, supera até mesmo a capital turística nacional carioca em quase três vezes mais visitantes, destes um terço a visita exclusivamente ${ }^{3}$, não oportunizando receitas turísticas em qualquer outro município. Segundo a mesma fonte, cerca de US\$311,00 são os gastos médios diários per capita do turista estrangeiro na cidade, com um periodo médio de 3,7 dias de permanência.

No mesmo documento, sabe-se que a hotelaria paulistana fatura mais de US $\$ 800$ milhões por ano com o turismo internacional (para 1 milhão de turistas estrangeiros na cidade em 1998). Porém, observando-se a pesquisa de 1996 do Serviço de Apoio às Micro e Pequenas Empresas de São Paulo (SEBRAE), e do São Paulo Convention \& Visitors Bureau (doravante SPC\&VB), apenas shopping centers $(80,8 \%)$, a vida noturna $(65,4 \%)$, casas de shows $(53,8 \%)$ e feiras ao ar livre $(53,8 \%)$ parecem ser conhecidos, aparentemente várias outras atrações de interesse turístico deixam de ser conhecidas. Como o principal motivo da viagem do turista à cidade é negócios/trabalho $(48,76 \%)$, e os dados acima demonstram a possível limitação da mobilidade do turista estrangeiro aos locais que circundam seu trabalho, reitera-se o imaginário comum de que São Paulo tem poucos atrativos, não podendo ser considerada uma cidade turística (Graciose, 1999), o que limitaria também as perspectivas dos visitantes com outros motivos de viagem como "turismo" $(39,94 \%)$ congressos / convenções $(9,64 \%)$

Analisando a infra-estrutura turística em São Paulo, a pesquisa sobre demanda turísticainternacional no Estado de São Paulo da Secretaria de Esportes e Turismo - SET (1998) também verificou que $25,67 \%$, ou seja, um quarto dos turistas

3. Dados da pesquisa de 1998 da Secretaria de Esportes e Turismo (SET) do Estado de São Paulo. Cidades mais visitadå por turistas estrangeiros: São Paulo (32,96\%) e Rio de Janeiro $(12,19 \%)$. estrangeiros qualificaram a sinalização turística como deficiente, e $27,81 \%$, regular, portanto, mais da metade $(53,48 \%)$ têm percepções negativas no que se refere a esse aspecto. Deste modo, faz-se necessária a investigação mais profunda acerca da comunicação e da linguagem verbal e não verbal que orientam a mobilidade do turista em São Paulo, passando a serem temas importantes para o estudo do turismo neste centro urbano. Dos turistas cujo fator decisório da visita é o turismo, um terço $(32,85 \%)$ o faz devido a atrativos turísticos e dois terços $(65,69 \%)$ em função visita a amigos e parentes. A pesquisa da SET o atribui à existência de inúmeras colônias de imigrantes e descendentes de imigrantes.

Esta investigação objetiva levantar recursos verbais e não verbais de sinalização facilitadores de acesso do turista estrangeiro aos destinos turísticos do município de São Paulo e verificar como o turista estrangeiro, em visita à cidade, reconhece a existência e a eficiência dessa sinalizaçãoem seu acesso a esses destinos.

\section{Consideraçōes Gerais}

Os critérios definidos para a escolha dos destinos turísticos a serem analisados foram, em primeiro lugar, a acessibilidade por meios de transporte públicos, especialmente o metrô e o ônibus, este último quando utilizado a partir de uma estação de metrô, partindo-se do pressuposto de que freqüentemente são os meios mais utilizados por turistas estrangeiros quando em seus deslocamentos sem um acompanhamento receptivo ${ }^{4}$.

$\mathrm{Na}$ pesquisa sobre demanda turística internacional no Estado de São Paulo da SET (1998), 12,24\% e 28,57\% dos turistas estrangeiros qualificam o transporte urbano como deficiente e regular respectivamente, ou seja, $40,81 \%$, quase a metade, o qualificam negativamente. A pesquisa do SEBRAE e do SPC\&VB informa que, dentre os meios de transporte utilizados pelos turistas estrangeiros, $73,1 \%$ utilizam-se de táxi, $69,2 \%$ de metrô e $57,7 \%$ de ônibus urbano. O táxi tem maiores graus de satisfacão. $21,1 \%$ acham-no ótimo e $57,8 \%$ bom. O metrô também apresenta elevados graus de satisfação por parte dos turistas estrangeiros: $38,9 \%$ qualificam-no como ótimo e $50 \%$ como bom. Já o ônibus urbano é qualificado negativamente: $6,6 \%$ ótimo, $20 \%$ bom, $46,7 \%$ regular e $26,7 \%$ ruim. As respostas seguem os padrões de qualificação de usuários habituais destes meios de transporte em São Paulo no que se refere ao conforto e possivelmente à eficiência do meio de transporte, porque o conceito de satisfação parte de uma percepção subjetiva do respondente. Essas informações não abrangem, de modo específico, a percepção da sinalização turística.

Como um segundo critério de escolha dos destinos, utilizou-se a freqüência

4. Entende-se por receptivo todo o serviço de recepção e acompanhamento do turismo em seus deslocamentos. 
com que os pontos de visitação aparecem em guias turísticos da cidade, cartõe postais e city tours efetuados por agências de receptivos a turistas.

Os dados foram coletados empiricamente através da observação direta da ocorrência de sinalização para acesso aos sessenta pontos de visitação turística selecionados, verificados um a um e com realização de registros fotográficos. A sinalização verbal e não verbal de acesso a cada um dos destinos definidos, quando existente, foi registrada fotograficamente, e os dados obtidos a partir das visitas, bem como documentos, tais como folhetos e mapas, foram analisados.

Um questionário, aplicado aos turistas estrangeiros, teve por objetivo conhecer sua percepção da sinalização com relação aos pontos de visitação e a eficiência da receptividade em língua estrangeira por parte dos funcionários dos locais visitados pelos respondentes, buscando refletir a percepção do turista no tocante a esses aspectos.

A combinação dos registros oriundos desses instrumentos de pesquisa e dos dados de pesquisas realizadas por órgãos oficiais possibilitou refletir o panorama com que se deparam os visitantes estrangeiros da cidade de São Paulo. A análise dos dados contou também com um levantamento de sinalização in loco e com questionários aplicados a esse tipo de visitantes.

\section{Sinalizaçāo de Acesso aos Pontos de Visitação}

A pesquisa sobre demanda turística internacional no Estado de São Paulo da SET (1998) apresenta que $46,52 \%$ dos turistas estrangeiros perceberam a sinalização dentro do Estado de modo satisfatório. Mais da metade do total $(53,48 \%)$ demonstraram sua insatisfação ao avaliarem essa sinalização como deficiente $(25,67 \%)$ e regular $(27,81 \%)$.

A publicação do SEBRAE e do SPC \& VB relata o percentual de turistas estrangeiros que conheceram a infra-estrutura urbana paulistana e seu grau de satisfação com ela. No que se refere à sinalização urbana, $69,2 \%$ se utilizaram desta infra-estrutura, dos quais $27,8 \%$ a consideram "boa", $44,4 \%$ "regular" e $27,8 \%$ "ruim". A conclusão apresentada é que,

ao contrário de outras cidades, São Paulo não possui qualquer sinalização em lingua estrangeira para orientaçāo dos visitantes (Sebrae e SPC \& VB, 1996:8)

A veracidade dessa afirmação genérica merece uma investigação específica que registre a ocorrência dessa falta de sinalização junto à localização dos pontos turísticos. Esta pesquisa buscou esse tipo de registro e selecionou os dados oriundos de 60 deles.

A coleta de registros fotográficos in loco e o instrumento do questionário aplicado a turistas permitiram refletir a realidade de sinalização paulistana em um enfoque mais específico, a partir do questionamento de onde e de como essa sinalização ocorre. O total de destinos contemplados nesta pesquisa efetivamente não é equivalente aos destinos que os turistas respondentes visitaram, uma vez que nas respostas aos questionários apenas 11 desse total de destinos foram mencionados.

Dos 60 destinos turísticos analisados, 29 possuem acesso sinalizado em português ${ }^{5}$. A sinalização é perceptível em placas nas ruas e avenidas de acesso ao locais em questão, placas a partir das estações de metrô e dos terminais de ônibus, e, sazonalmente, em eventos específicos, como por exemplo a Fórmula I, no Autódromo José Carlos Pace (Interlagos), e exposições no Museu de Arte de São Paulo (MASP), Bienal e Museu Paulista (Ipiranga). No total, 22 dos 60 destinos possuem sinalização nas ruas ou avenidas de acesso, 9 na estação de metrô mais próxima, 5 nos pontos de ônibus e 4 emeventos específicos. Os destinos sinalizados nas ruas e avenidas de acesso totalizam praticamente um terço do total de destinos.

Em terminais e pontos de ônibus, verificou-se que apenas 5 destinos são sinalizados a partir do terminal da Barra Funda: o Memorial da América Latina, o Museu de Arte Sacra, o Museu de Arte Moderna (MAM), o MASP e a Pinacoteca do Estado, com placas específicas do chamado Turismo Cultural, um roteiro patrocinado pela Secretaria de Esportes e Turismo, pela EMBRATUR e pela Continental Airlines que sai desse terminal de ônibus.

Os destinos sinalizados a partir do metrô são: o bairro da Liberdade; a Catedral da Sé; o Centro Cultural São Paulo; o Edifício do SESI (Serviço Social da Indústria); a Estação da Luz; o MASP; o Memorial da América Latina; o Parque Trianon (Ten. Siqueira Campos) e o SESC (Serviço Social do Comércio) Vila Mariana. Outros pontos, apesar de merecedores de um maior cuidado em relação à sua divulgação não o receberam, ainda que próximos às estações de metrô, nem mesmo tendo o metrô recentemente lançado uma campanha de uso desse meio de transporte enquanto acesso a pontos turísticos próximos às suas estações. É o caso da Casa das Rosas, do Centro Cultural Jabaquara, do Edifício Itália, do Instituto Cultural Israelita Brasileiro, do Itaú Cultural, do Marco Zero de São Paulo, do Memorial do Imigrante, dos museus de Arte Sacra, da Imigração Japonesa, Lasar Segall, São Bento, do Palácio das Indústrias, do Pátio do Colégio e do Museu Padre Anchieta, da Pinacoteca do Estado, do Parque da Luz, do Solar da Marquesa de Santos, do Teatro Municipal e do Museu do Teatro Municipal.

Quando existente (Tabela 1), a sinalização em ruas próximas aos locais de visitação aqui analisados é similar às demais indicações do município, em placas verdes que indicam bairros, hospitais, ruas e demais vias de acesso. Em alguns destinos, como o Recinto de Exposições do Parque da Água Funda (Secretaria da Agricultura), as indicações são abundantes e em outros como, por exemplo, o Museu de Arte Sacra somente se encontra uma placa a alguns metros do local.

5. Sinalizaçāo de acesso é considerada toda e qualquer indicação visual, verbal e não verbal, disponivel nos locais, que em placas, quer em sinalização eletrônica, sinalização de solo etc., desconsiderando-se propaganda veiculada através de outdoors. 
TABELA 1 - SINALIZACCÃO DE DESTINOS TURISTICOS PAULISTANOS

\begin{tabular}{|c|c|c|c|c|}
\hline . & Destino & $\begin{array}{c}\text { Com } \\
\text { Sinalizaçăo }\end{array}$ & $\begin{array}{l}\text { Localização da } \\
\text { Sinalização }\end{array}$ & $\begin{array}{c}\text { Sinalização Interna } \\
\text { p t turista Estrangeiro }\end{array}$ \\
\hline 1 & Autódromo de Interlagos & 凶 & EV & ID \\
\hline 2 & Bairro da Liberdade & 凶 & MERU & ID \\
\hline 3 & Casa das Rosas & & & \\
\hline 4 & Catedral da Sé & 凶 & ME: & \\
\hline 5 & C. Cultural Jabaquara & 凶 & $\mathrm{RU}$ & \\
\hline 6 & Centro Cultural S.P. & 凶 & ME & \\
\hline & Cidade Universitária & 凶 & RU & \\
\hline 8 & Ed. A.Arantes-BANESPA & & & ID \\
\hline & Ed. Itália & - & & ID, IS \\
\hline 10 & Ed. Patriarca - BANESPA & & & \\
\hline 11 & Ed. SESI & 凶 & ME & \\
\hline 12 & Estação da Luz & 凶 & ME RU & \\
\hline 13 & Ginásio do Ibirapuera & 凶 & RU & \\
\hline 14 & Horto Florestal & 凶 & RU & \\
\hline 15 & Instituto Butantã & 凶 & RU & ID, IS, FL \\
\hline 16 & Inst. Cult. Israelita / Bras. & . & & \\
\hline 17 & Itaú Cultural & - & & \\
\hline 18 & Jd. Botânico & & & \\
\hline 19 & Jd. Zoológico & 凶 & RU & ID \\
\hline 20 & MAM & 凶 & $\mathrm{OB} R \mathrm{RU}$ & ID, IS , FL \\
\hline 21 & Marco Zero de São Paulo & & & \\
\hline 22 & MASP & $凶$ & EV ME OB & IS \\
\hline 23 & Memorial da Am. Latina & $凶$ & ME OB RU & \\
\hline 24 & Memorial do Imigrante & & & \\
\hline 25 & Mon. às Bandeiras & $凶$ & RU & \\
\hline 26 & Mon. à Independência & - & & \\
\hline 27 & Mon. P. Álvares Cabral & - & & \\
\hline 28 & Museu de Aeronáutica & & & \\
\hline 29 & Museu de Arte Sacra & 凶ा & OB KU & ID, IS, FL \\
\hline 30 & Museu da Casa Bras. & & & \\
\hline 31 & Museu do Folclore & - & & \\
\hline 32 & Museu da Im. Japonesa & - & & $\mathrm{DD}$ \\
\hline 33 & Museu Lasar Segall & - & & \\
\hline 34 & Museu Paulista & 凶 & EV RU & \\
\hline 35 & Museu Pe. Anchieta & - & & \\
\hline 36 & Museu São Bento & - & & \\
\hline 37 & Museu do Relógio & - & & \\
\hline 38 & Museu de Zoologia & - & & \\
\hline 39 & Obelisco & & & \\
\hline 40 & Palácio das Indústrias & 凶 & RU & \\
\hline 41 & Páteo do Colégio & - & & ID, FL \\
\hline 42 & Pavilhão da Bienal & - & & \\
\hline 43 & Pavilhão Japonês & & & \\
\hline 44 & Pico do Jaraguá & $凶$ & RU & \\
\hline 45 & Pinacoteca do Estado & 凶] & $\mathrm{OB}$ & \\
\hline 46 & Planetário & & & $\mathrm{ID}$ \\
\hline 47 & Playcenter & 凶 & RU & \\
\hline 48 & Pq. da Aclimaçāo & 凶 & $\mathrm{RU}$ & \\
\hline 49 & Pq. da Água Branca & 凶 & $\mathrm{RU}$ & \\
\hline 50 & Pq da Agua Funda & 凶 & EV RU & \\
\hline 51 & $\mathrm{Pq}$ do Ibirapuera & - & & \\
\hline 52 & Pq. da Luz & - & & \\
\hline 53 & Pq da Mônica & $\therefore$ & & ID \\
\hline 54 & Pq Trianon & $凶$ & $\mathrm{ME}$ & \\
\hline 55 & SESC Pompéia & 凶 & $\mathrm{RU}$ & \\
\hline 56 & SESC Vila Mariana & $凶$ & ME RU & \\
\hline 57 & Simba Safári & $凶$ & $\mathrm{RU}$ & \\
\hline 58 & Solar da Marq. Santos & - & & \\
\hline \multirow{3}{*}{$\begin{array}{l}59 \\
60 \\
\end{array}$} & Teatro Mun. e Museu & - & & \\
\hline & Viaduto do Chá & - & & \\
\hline & TOTAL & 29 & * & $* *$ \\
\hline
\end{tabular}

Portanto, em 30 dos destinos turísticos analisados, (50\%) não possuem acesso sinalizado. E na lista dos destinos a seguir, retira-se o Parque do Ibirapuera. São eles: a Casa das Rosas, o Edifício Altino Arantes (Torre do BANESPA), o Edifício Itália, o Edifício Patriarca (prédio do BANESPA onde se localiza o Jardim Walter Galera), o Instituto Cultural Israelita Brasileiro, o Itaú Cultural, o Jardim Botânico, o Marco Zero de São Paulo, o Memorial do Imigrante, os monumentos à Independência e Pedro Álvares Cabral, os museus da Aeronáutica, da Casa Brasileira, do Folclore, da Imigração Japonesa, Lasar Segall, Padre Anchieta, São Bento, do Relógio, de Zoologia, o Obelisco do Ibirapuera, o Pátio do Colégio, o Pavilhão da Bienal, o Pavilhão Japonês, o Planetário, os Parques do Ibirapuera, da Luz e da Mônica, o Solar da Marquesa de Santos, o Teatro Municipal e seu Museu e o Viaduto doChá. Destes, alguns são destinos que certamente deveriam merecer maior cuidado com relação à recepção de turistas estrangeiros, já que são bastante divulgados em guias turísticos, comoé o caso do Edifício Itália, doJardimBotânico, do Monumento à Independência, do Obelisco, do Parque do Ibirapuera, do Pátio do Colégio, e o Museu Padre Anchieta, do Teatro Municipal e do Viaduto do Chá, que possuem alto valor histórico para São Paulo.

O levantamento aqui realizado revela que a maioria dos destinos não dispõe de sinalização a partir dos meios de transporte público. De acordo com a pesquisa do SEBRAE do SPC \& VB sobre informações turísticas, os locais onde os turistas mais obtêm informações turísticas são as Centrais de Informação Turística (CITs $50 \%)$, a recepção do hotel $(38,5 \%)$, amigos $(23,1 \%)$, entre outros. As informações mais solicitadas são "informações gerais e da cidade", seguidas de "atrativos" e de "restaurantes", incluindo, entre outros, "localização", "mapa de cidade", "acessos" e "folhetos sobre a cidade". Pode-se deduzir que o turista provavelmente terá dificuldades de acesso aos destinos turísticos da cidade quando o faz por si mesmo, uma vez que a sinalização de acesso é importante para o visitante que se desloca sem o auxílio de um receptivo. Sua mobilidade dependeria de mapas, nem sempre disponíveis, e de indicações mediadas por informações orais fornecidas por funcionários de locais de hospedagem, CITs e até mesmo transeuntes, o que incorreria em uma oportunização de ruídos de comunicação e sua conseqüente dificuldade em mover-se pela cidade de modo satisfatório.

\section{Destino Turístico e Sinalizaçāo Interna}

Pressupõe-se que o turista estrangeiro que não dispõe de um receptivo seja capaz de compreender inglês e/ou espanhol - idiomas tradicionalmente associados ao turismo internacional. Foram considerados como sinalização interna específica para o turista estrangeiro aqueles destinos com informações nesses idiomas, bem como sinalizações não verbais, internacionalmente reconhecíveis, como no caso de placas indicativas de proibido fotografar, etc. (Tabela 1). 
Os registrosfotográficosrealizadosemcada local e o material disponibilizado internamente podem ser classificados em: indicações, instruções, explicações e folhetos. Indicações podem incluir placas ou pinturas, em parede ou até mesmo no solo, que mostrem o acesso aos pontos ou motivos de visitação interna. Instruções são diretrizes de ação no local, tais como onde é ou não permitido fotografar, fumar, etc. Explicações de gravuras, esculturas, exposições ou mesmo do histórico do local podem ocorrer tanto através de funcionários quanto através de placas. As placas constituem-se na forma em que indicações, instruções e explicações são expressos Quanto aos folhetos, serão considerados apenas aqueles distribuídos gratuitamente. Apenas 12 dos destinos pesquisados apresentam alguma sinalização interna para o turista estrangeiro. Um deles é o Instituto Butantã onde as indicações e explicações de animais em exposição, instruções e folhetos são oferecidos em inglês e, em alguns casos, francês, espanhol e alemão, diferentemente do Zoológico, cujas informações em inglês restringem-se às explicações dos animais. Outros, que disponibilizam sinalização interna, são o Pátio do Colégio e o Museu Padre Anchieta, nos quais as informações estão em vários idiomas na entrada e há explicações sobre o local e acerca de peças expostas (em inglês), bem como folhetos em espanhol e em inglês. Quanto ao Parque da Mônica, há uma indicação em inglês, somente na entrada. O Autódromo de Interlagos constitui-se uma exceção porque a maioria das placas internas é retirada após os eventos de Fórmula I, nos demais eventos a sinalização restringe-se ao uso do português.

O Parque Ibirapuera disponibiliza uma série de destinos turísticos dentro do próprio parque, como no caso da Bienal e do Planetário. É importante ressaltar que a sinalização indicativa desses destinos restringe-se à língua portuguesa. Embora situando-se dentro do parque, essa sinalização, assim como toda a sinalização de acesso dentro da cidade, limita-se aos nomes dos locais (ex. "Planetário").

$\mathrm{Na}$ Tabela 1 não foram classificados como oferecendo sinalização interna ao turista estrangeiro o Planetário e o Centro Cultural São Paulo. No primeiro porque não se pode considerar como sinalização em língua estrangeira a indicação de toilettes, pois a palavra tem o mesmo significado em português. No segundo, as indicações em língua estrangeira, no caso, árabe e inglês, são encontradas somente em algumas exposições, como é o exemplo da exposição "Memórias áraboislâmicas em Portugal", provavelmente porque tratam-se de temas de cunho internacional. Os funcionários do laboratório de línguas existente nesse espaço falam inglês, porém somente o fazem quando procurados por algum usuário do laboratório. Os demais departamentos do espaço cultural não dispõem de funcionários falantes de línguas estrangeiras para o atendimento ao público em geral. Um último destino em que se constatou a existência sazonal de sinalização em inglês foi o Pavilhão da Bienal, onde apenas algumas exposições foram sinalizadas.

Dos 60 pontos pesquisados, 48 não possuem sinalização interna específica para turistas estrangeiros. É o caso da Estação da Luz que, apesar de haver sido implementada por uma companhia estrangeira, não dispõe de sinalização interna em língua inglesa. Nem mesmo o Posto de Atendimento aoUsuário oferece informações ou um funcionário para atendimento nesse idioma. De acordo com os funcionários desse posto, na Central de Atendimento da CPTM (Companhia Paulista de Trens Metropolitano), que não é visível ao público em geral, há um atendente, pronto a dar informações sobre o histórico do lugar em inglês. No Jardim Botânico não há sinalizaçãointerna em inglês. Segundo uma das monitoras dolocal, os monitores não falam inglês. Apesar de a tradição européia de visita aos jardins botânicos ser internacionalmente difundida, a comunicação do turista estrangeiro nesse local não é considerada.

Outro exemploé o Memorial da América Latina, onde se pressupõe abundância de informações em espanhol, principalmente no Pavilhão da Criatividade. Nesse local há uma exposição permanente sobre grande parte dos países latino-americanos, cujas informações são em português e só há monitores falando em inglês sob reserva. Os funcionários, quando consultados a esse respeito, alegam que estrangeiros têm seus próprios guias, não necessitando de monitores bilíngües locais. Somente há a ocorrência da língua espanhola dentro do Anexo aos Congressistas, local que é mais freqüentado por representantes de governos e relativamente pouco visitado por turistas de um modo geral. O mesmo ocorre no Memorial do Imigrante, no qual a preocupação específica com a sinalização em idiomas estrangeiros é inexistente, já que as informações em outros idiomas somente são utilizadas na documentação exposta. Diferentemente, o Museu da Imigração Japonesa dispõe de indicações em inglês e japonês, proporcionando melhor acesso aos visitantes internacionais.

Também o Museu Paulista e o Monumento à Independência, destinos históricos tradicionais incorrem na falta de preocupação em receber o turista estrangeiro interessado em conhecer mais sobre a história brasileira.

Portanto, a falta de sinalização interna em $80 \%$ dos destinos turísticos em análise não facilita a visita do turista estrangeiro. A qualidade da visita dos freqüentadores de idioma estrangeiro poderia aumentar se houvesse sinalização verbal em inglês e espanhol, ou até mesmo não verbal.

A partir dessas informações, a pesquisa passou para a fase de coleta de dados junto a uma pequena amostragem de turistas que responderam a um questionário sobre a qualidade da sinalização dos destinos turísticos que visitaram em São Paulo (Anexo "Tourist destination acess questionnaire").

\section{Qualidade de Informaçōes em Destinos Turísticos Paulistanos}

O objetivo do questionário, aplicado a 32 turistas, era de saber como o turista percebia a sinalização visual a caminho dos destinos turísticos, a informação escrita disponível no local e a eficiência comunicativa dos funcionários. Do total de respondentes, 20 foram contatados no Aeroporto Internacional de São Paulo/ Guarulhos, no momento do seu embarque, e 12 em um Albergue da Juventude, situado na zona Sul do município (bairro da Saúde). 
A idade dos turistas variou entre as faixas de 15 a 24 anos e 45 a 65 anos. Nenhum dos turistas tinha mais de 65 anos de idade. Dos respondentes, quatro tinham entre 15 e 24 anos, doze entre 25 e 44 anos e quatorze entre 45 e 65 anos e dois não forneceram essa informação. No tocante à origem, quinze dos entrevistados procediam da Europa (dos quais onze da França), sete da América do Norte (Estados Unidos da América), três da América do Sul, três da África e apenas dois da Oceania e dois da Ásia (Singapura).

Como o questionário abria a possibilidade de que o respondente declarasse qualquer idioma que ele falasse, as línguas mencionadas foram, primeiramente, inglês (25 menções), em segundo lugar, francês (16), em terceiro lugar, português (7), seguidos por alemão (6), espanhol (3), árabe (2), italiano (1), chinês (1), e línguas nativas (3). Foi possível notar que alguns respondentes somente responderam a questão citando o idioma estrangeiro, desconsiderando sua(s) língua(s) materna(s), a exemplo de um francês que mencionou apenas inglês e português.

Na questão sobre o principal motivo da visita ao Brasil, era possível a menção de mais de uma possibilidade. As razões mais citadas foram lazer/turismo (23) e negócios (10), seguidos por interesses culturais (4), motivos familiares (4), sociais (3), educacionais/científicos (3), ecológicos (2) e religiosos (2).

Solicitou-se ao turista que mencionasse cinco destinos turísticos que tivesse visitado durante sua estada na cidade, explicitando o meio de transporte que utilizou, sua percepção qualitativa da comunicação no acesso a cada um deles, bem como da informação escrita disponível sobre o destino e também sua percepção da eficiência de receptivos do local. No entanto, apesar de ser uma questão formulada com alternativas, a maioria dos respondentes (21) a desconsiderou. Quando questionados pessoalmente pelas pesquisadoras sobre o motivo de tal omissão, freqüentemente alegavam estar nesta cidade apenas de passagem ou a negócios, permanecendo por poucas horas. Os destinos citados foram: Avenida Paulista, bairros da Liberdade e Pinheiros, Catedral da Sé, Centro Cultural São Paulo, Cidade Universitária, Edifício Itália, Estádio do Morumbi, Instituto Butantã, Jardim Botânico, Jardim Zoológico, MASP, Parque Ibirapuera, Praça da República, Serra da Cantareira, Shopping Center Ibirapuera, Shopping Center Morumbi e Teatro Municipal. Em relação àqueles pesquisados na fase de registro de sinalização disponível a caminho e nos destinos turísticos, a correspondência é apenas parcial. Serão comparados somente os dados procedentes dos destinos coincidentes aos 60 pontos turísticos anteriormente analisados (Tabela 1).

A percepção individual dos turistas acerca de cada destino, no que concerne ao meio de transporte utilizado, sinalização a caminho, informação escrita disponível e eficiência comunicativa no idioma de recepção dos funcionários do local, pode ser observada na Tabela 2
TABELA 2 - TRANSPORTE E QUALIDADE DE INFORMAÇÕES

\begin{tabular}{|c|c|c|c|c|}
\hline Destino & Transporte & Sinalização & Inf. Escrita & Receptivo \\
\hline $\begin{array}{l}\text { B. Liberdade } \\
\text { C. da Sé } \\
\text { C. Cultural SP } \\
\text { C. Universitária } \\
\text { Ed. Itália } \\
\text { I. Butantã } \\
\text { Jd. Botânico } \\
\text { Jd Zoológico } \\
\text { MASP } \\
\text { Pq. Ibirapuera } \\
\text { T. Municipal }\end{array}$ & 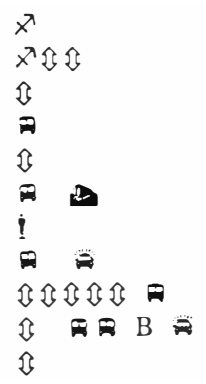 & 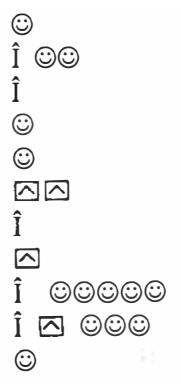 & 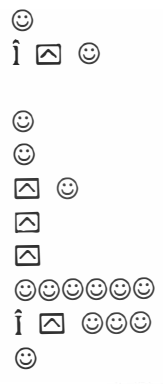 & 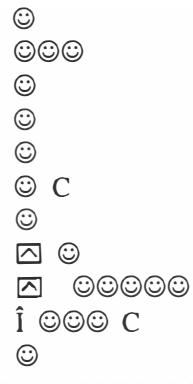 \\
\hline
\end{tabular}

Cada icone equivale ao total de respondentes daquele item

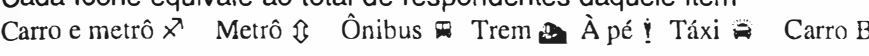
Inexistente:

É possível notar que para o estrangeiro que visitou o bairro da Liberdade, utilizando-se de carro e metrô, tanto a sinalização quanto a informação escrita disponível e a comunicação de receptivos foram boas.

Dois visitantes da Catedral da Sé, ao utilizarem o metrô, perceberam a sinalização de acesso de modo positivo, mas aquele que foi de automóvel, a considerou inexistente. Quanto à informação escrita, não houve um consenso, diferentemente da eficiência comunicativa do receptivo, que foi, por unanimidade, considerada boa.

O estrangeiro que foi ao Centro Cultural São Paulo de metrô, não reconheceu a existência de sinalização e considerou o receptivo do local eficiente. Porém, aquele que dirigiu-se à Cidade Universitária de ônibus, qualificou os três aspectos de modo positivo, bem como o visitante do Edifício Itália, apesar de haver, nesse caso, utilizado o metrô como meio de acesso.

Ônibus e trem foram os meios de transporte utilizados pelos estrangeiros que foram ao Instituto Butantã, possivelmente por essa razão, julgaram a sinalização de acesso regular. Também essa foi a avaliação de um deles sobre a informação escrita no local, já o outro a avaliou como boa. Suas opiniões sobre a eficiência da comunicação dos funcionários também não foram semelhantes, para um deles foi confusa, e para o outro, boa.

O respondente que visitou o Jardim Botânico a pé não foi auxiliado pela sinalização a caminho, tampouco pela informação escrita no local (regular), porém avaliou como boa a eficiência dos funcionários receptivos. Os transportes utilizados por turistas a caminho do Jardim Zoológico foram ônibus e táxi, onde a sinalização a caminho e a informação escrita existente foram avaliadas como regulares por um 
de seus visitantes, já o outro deixou de avaliá-las. O receptivo foi reputado por um deles como regular e por outro como bom.

O destino turístico mais mencionado pelos respondentes do questionário fo o MASP. Cinco deles o visitaram via metrô e um deles via ônibus. Dos seis, cinco julgaram a sinalização de acesso como boa e um deles, aquele que se utilizou do ônibus, não a encontrou. Para todos eles a informação escrita foi boa, assim como a comunicação dos funcionários, excetuando-se um dos respondentes que considerou este último item como regular.

O segundo lugar de maior menção nos questionários foi o Parque Ibirapuera, cujo acesso foi feito através do metrô por apenas um deles, por dois deles de ônibus, um de carro e um de táxi. A sinalização a caminho do parque e a informação escrita disponível foram tidas como inexistentes para um deles e como regulares para outro, enquanto os demais as reputaram como boas. O receptivo foi confuso para um deles, inexistente para um outro e bom para os restantes.

Visitado de metrô por apenas um estrangeiro, o Teatro Municipal recebeu dele a avaliação de bom nos três aspectos.

De um modo geral, a percepção dos respondentes referenda os dados obtidos a partir dos registros coletados na primeira fase desta pesquisa. A sinalização existente no bairro da Liberdade, na Catedral da Sé, na Cidade Universitária, no Instituto Butantã, no Jardim Zoológico, no MASP e no Parque do Ibirapuera foi reconhecida pelos visitantes estrangeiros, embora em alguns casos a avaliassem como regular. Até mesmo a inexistência de sinalização do Jardim Botânico foi manifestada.

As respostas dos questionários revelaram que a visualização da sinalização de acesso ao Parque do Ibirapuera não foi notada por um de seus visitantes. O mesmo aconteceu com o Centro Cultural São Paulo, ao passo que, um respondente assinalou essa sinalização como boa em direção ao Edifício Itália e um outro ao Teatro Municipal, mas, no entanto, a primeira fase da pesquisa demonstrou que esses destinos não apresentam sinalização de acesso. Possivelmente houve uma interpretação equivocada por parte desses turistas, que podem ter confundido sinalização de acesso com informações no próprio local.

Como o enfoque desta pesquisa é a sinalização disponível para os turistas que se utilizam de meios de transporte público em seus deslocamentos em direção a destinos turísticos, o último item do questionário contemplou esse aspecto, buscando levantar como o turista que os utilizou avaliava sua sinalização, seu conforto e sua eficiência. As respostas oriundas dos dados coletados no Albergue da Juventude foram aquelas em que os turistas puderam se manifestar sobre esse tipo de transporte. Os respondentes abordados no Aeroporto Internacional de São Paulo não responderam essa questão, com uma única exceção. Pode-se atribuir essa omissão ao fato de, por estarem, em sua maioria, viajando a negócios, não haverem disponibilizado tempo para deslocarem-se até destinos turísticos, ou ainda por terem sido transportados a esses destinos através de meios fornecidos pelas empresas com as quais mantinham relações de negócios e, possivelmente, tendo o auxílio de receptivos.

Dos sete usuários de ônibus, quatro consideraram sua sinalização boa, enquanto os demais a avaliaram como regular, confusa e inexistente. Quanto ao conforto, quatro o julgaram como regular, dois bom e um delesalegou ser inexistente. Já a eficiência foi tida como boa por três respondentes, regular por dois, e inexistente por outros dois. Dos nove usuários de metrô que se manifestaram sobre sua sinalização, a maioria (oito) a consideraram boa, apenas um a qualificou como regular. O conforto e a eficiência do metrô foram, por unanimidade, avaliados como bons. É importante ressaltar que nem todos os respondentes que manifestaram a

sinalizaçao, o conforto e a eficiencia de ambos os meios.

\section{Consideraçōes Finais}

Os fatores psicológicos que entram na decisão do turista em adquirir um serviço são: percepção, aprendizado, personalidade, motivos e atitudes (Beni, 1998). O acesso à informação entra aqui como um fator de risco que pode influenciar o turista consumidor em sua decisão de compra, pois sabemos que

a informaçāo bem administrada é mercadoria muito valiosa que garante riqueza, poder e legitimidade ao seu proprietário. Sua verdade é a eficiência. Seu resultado, o bom desempenho (Trigo, 1998:27).

A efïciência da comunicação enquanto orientação à mobilidade espacial é essencial para a otimização da receptividade do turista estrangeiro na cidade-alvo, uma vez que as informações podem ser simultaneamente motivadoras e viabilizadoras de seu deslocamento em direção aos pontos turísticos.

Conforme a pesquisa da SET sobre demanda turística internacional no Estado de São Paulo, sabe-se que a origem dos turistas estrangeiros que visitam São Paulo é, em sua maioria, de países com os quais o Brasil mantém estreitas relações com

\section{Amé}

da cidade de São Paulo no âmbito do turismo de negócios. No caso do turista estrangeiro, sua orientação depende do sistema informativo que garante ou dificulta o acesso a esses locais, conseqüentemente, questões da linguagem utilizada na sinalização indicativa dos pontos turísticos e da comunicação passam a ser de

6. Seguem-se: Alemanha: 30.443 , Itália: 19.111, Japāo: 15.919, Uruguai: 14.311, Chile: 13.118, França: 12.365 ,
Suiça: 12.123. 
extrema importância, principalmente no tocante à lingua inglesa, que vem a ser a língua franca do turismo internacional.

De acordo com a pesquisa do SEBRAE e do SPC\&VB, os turistas estrangei ros propõem a produção de um mapa da cidade de São Paulo com os trajetos mais utilizados com indicação de aeroportos, atrativos, hotéis, etc. como sugestão para melhorar o receptivo da cidade, que poderia ser distribuído nas locadoras de veículos, nos hotéis, nos aeroportos, nos postos de informações. Há também a sugestão da implantação de um sistema de sinalização turística na cidade de São Paulo (Sebrae e SPC \& VB, 1996:17). Em campo, ao investigar a sinalização do acesso aos destinos turísticos a partir de meios de transporte coletivo e aquela disponível nos próprios destinos, foi possível constatar motivos que suportam a pertinência dessas sugestões.

Primeiramente verificaram-se ausências e deficiências na sinalização turística oferecida em língua inglesa e também em linguagem não verbal (visual). Em segundo lugar foi possível perceber que essas deficiências ocorriam tanto em direção a esses destinos quanto dentro deles. E, finalmente foi possivel notar o reconhecimento de um receptivo de funcionários satisfatório à percepção de visitantes estrangeiros.

A falta de qualidade da sinalização aqui constatada revela a falta de planejamento de disponibilizá-la, como no caso do Jardim Botânico, ou ainda, como no caso do MASP e do Parque Trianon, cuja sinalização dentro do metrô é de difícil percepção porque a plataforma é grande e só é visível em um dos lados das saídas impossibilitando a visualização de alguém que saia pelo outro lado. A sinalização da cidade de São Paulo revela desconsiderar a percepção de um turista não falante de português, buscando adequar e facilitar-lhe o acesso aos destinos turísticos quando de seu deslocamento sem o auxílio de receptivos.

A partir desses resultados nota-se a necessidade de maior participação e contribuição de profissionais de turismo para o aprimoramento da recepção de estrangeiros na cidade desenvolvendo o turismo em São Paulo, considerando-se que a linguagem no estudo da sinalização, voltada para os meios de transporte de São Paulo, é de extrema relevância, principalmente tendo em vista o deslocamento do turista usuário dos meios de transporte urbano em sua mobilidade na busca dos pontos turísticos da cidade. Mesmo quando essa sinalização existe (em apenas um terço dos destinos que aqui foram investigados) não é específica para turistas, pois está disponível em placas verdes, assim como as demais informações dentro do município, voltadas para o auxílio ao cidadão que se desloca utilizando o automóvel como meio de transporte.

Esse quadro reforça a necessidade de formação de mão-de-obra qualificada para atuar tanto no planejamento turístico da cidade quanto no receptivo de turistas estrangeiros. No primeiro caso, esse profissional precisaria de uma conscientização das deficiências, a partir das quais seria possível elaborar um plano de implementação de um sistema de sinalização que contemplasse esse aspecto de modo a facilitar o deslocamento de turistas, com especial atenção às dificuldades enfrentadas po estrangeiros, que têm no idioma não familiar um fator limitante. No caso do receptivo, depreende-se a importância de um ensino de idiomas instrumental e reflexivo nos cursos de formação de turismólogos. O estudante não poderia limitarse a ser um usuário de um idioma estrangeiro, ele precisaria ser capacitado a fazer desse conhecimento um instrumento a mais de transformação de sua práxis como planejador.

A natureza interdisciplinar da pesquisa aqui proposta possibilitou a reflexão de um mesmo tema sob a visão do geógrafo e do pesquisador da linguagem, possibilitando o contato e o intercâmbio de conhecimento entre pesquisadores como amplamente defende Rejowski (1996). Ao investigar a bibliografia nas áreas de Geografia, Língua Inglesa e Comunicação, constatou-se a falta de pesquisas que lidassem com o tema da sinalização internacional enquanto elemento facilitador do turismo internacional a esta cidade em particular. O tema da sinalização e da comunicação visual voltada para o turista estrangeiro tem sido pouco explorado pela academia, inclusive pela Geografia e é pratícamente desconhecido da Lingüística Aplicada e da Comunicação. Seria necessária uma ação imediata no sentido institui uma sinalização específica para o turista de um modo geral. A contribuição desta pesquisa limitou-se a constatar a necessidade de pesquisas-ação que partam em busca de solucionar o problema de sinalização facilitadora do deslocamento do turista estrangeiro no município de São Paulo.

\section{Referências Bibliográficas}

BENI, M. C. 1998. Análise listrutural do Turismo. São Paulo: Ed. SENAC.

GRACIOSE, V. F. 1999. Turismo e metrô: parceria viável Tlurismo em Análise, São Paulo: ECA-USP, v.10, n. p. 58-74.

REJOWSKI, M. 1996. Turismo e pesquisa cientifica: pensamento internacional $x$ siluação hrasileira. Campinas: Papirus

SEBRAE - SERVIÇO DE APOIO AS MICRO E PEEUENAS EMPRESAS DE SÃO PAULO; SPC\&VB - SÃO PAULO CONVENTION E VISITORS BUREAU. 1996. Perfil do turismo receptivo da cidade de São Pauloprincipais conclusĩes. São Paulo: HB Ed. Hotéis do Brasil.

SECRETARIA DE ESPORTES TURISMO DE SAO PAULO. 1998. Pesciquisasohre demanda uristica internacional

(enfoque Estado de São Paulo). São Paulo: Coordenadoria de Turismo.
TRIGO, L. G. 1993. Turismo e qualidade: rendências contemporâneas. Campinas, Papirus

\section{Recebido em 2/7/2000}

Aprovado em 4/10/2000 


\section{ANEXO - TOURIST DESTINATION ACCESS QUESTIONNAIRE}

1. Age: ( ) 15 to 24 ( ) 25 to 44 ( ) 45 to 65 anos ( ) over 65

2. Where are you from? Country: City:

3. Which languages do you speak?

4. What is the main reason you are visiting Brazil?

( ) leisure

( ) ecological interests

( ) educationall scientific (participation in congresses, seminars)

( ) cultural interests

( ) health care

() religious affairs

() business

( ) sport practicing

( ) social affairs

() family affairs

( ) others I which?

5. Mention five tourist destinations you have visited in São Paulo during the present trip:

\begin{tabular}{|c|c|c|c|c|}
\hline Place & How did you get there? & $\begin{array}{l}\text { How was the } \\
\text { visual si gnaling } \\
\text { to wards the site? }\end{array}$ & $\begin{array}{l}\text { How was the witten } \\
\text { informations ab out } \\
\text { the site? }\end{array}$ & $\begin{array}{l}\text { How was the } \\
\text { reception staff } \\
\text { comminicatiorlan- } \\
\text { guage efficiency? }\end{array}$ \\
\hline a) & 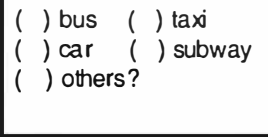 & $\begin{array}{lll}( & \text { ( ) good } \\
\text { ( ) } & \text { not so good } \\
\text { ( ) } & \text { confusing } \\
\text { ( ) } & \text { non existent }\end{array}$ & $\begin{array}{ll}\text { ( ) } & \text { good } \\
\text { ( ) not so good } \\
\text { ( ) confusing } \\
\text { ( ) non existent }\end{array}$ & $\begin{array}{lll}(\text { ( ) } & \text { good } \\
(\text { () } & \text { not so good } \\
\text { ( ) } & \text { confusing } \\
( & \text { ) } & \text { non existent }\end{array}$ \\
\hline b) & $\begin{array}{l}\text { ( ) bus ( ) taxi } \\
\text { ( ) car ( ) subway } \\
\text { ( ) others? }\end{array}$ & $\begin{array}{lll}\text { ( ) } & \text { good } \\
\text { ( ) not so good } \\
\text { ( ) } \text { confusing } \\
\text { ( ) non existent }\end{array}$ & $\begin{array}{lll}\text { ( ) } & \text { good } \\
\text { () not so good } \\
\text { ( ) } \text { confusing } \\
\text { ( ) } \text { non existent }\end{array}$ & $\begin{array}{lll}\text { () } & \text { good } \\
\text { () } & \text { not so good } \\
\text { ( ) } \text { confusing } \\
\text { ( ) } \text { non existent }\end{array}$ \\
\hline c) & $\begin{array}{l}\text { ( ) bus ( ) tax } \\
(\text { ) car ( ) subway } \\
(\text { ) others? }\end{array}$ & $\begin{array}{ll}\text { ( ) } & \text { good } \\
\text { ( ) } & \text { not so good } \\
\text { ( ) } & \text { confusing } \\
\text { ( ) } & \text { non existent }\end{array}$ & $\begin{array}{ll}\text { ( ) } & \text { good } \\
\text { ( ) not so good } \\
\text { ( ) confusing } \\
\text { ( ) } \text { non existent }\end{array}$ & $\begin{array}{lll}\text { ( ) } & \text { good } \\
\text { () } & \text { not so good } \\
\text { ( ) } \text { confusing } \\
\text { ( ) } & \text { non existent }\end{array}$ \\
\hline d) & $\begin{array}{l}\text { ( ) bus ( ) taxi } \\
\text { ( ) car ( ) subway } \\
\text { ( ) others? }\end{array}$ & $\begin{array}{lll}\text { ( ) } & \text { good } \\
\text { ( ) } & \text { not so good } \\
\text { ( ) } & \text { confusing } \\
\text { ( ) } & \text { non existent }\end{array}$ & $\begin{array}{lll}\text { ( ) } & \text { good } \\
\text { ( ) not so good } \\
\text { ( ) confusing } \\
\text { ( ) } \text { non existent }\end{array}$ & $\begin{array}{lll}\text { ( }) & \text { good } \\
(\text { () } & \text { not so good } \\
\text { ( ) } & \text { confusing } \\
\text { ( ) } & \text { non existent }\end{array}$ \\
\hline e) & $\begin{array}{l}\text { ( ) bus ( ) taxi } \\
\text { ( ) car ( ) subway } \\
\text { ( ) others? }\end{array}$ & $\begin{array}{lll}\text { ( ) } & \text { good } \\
\text { ( ) } & \text { not so good } \\
\text { ( ) } & \text { confusing } \\
\text { ( ) } & \text { non existent }\end{array}$ & $\begin{array}{lll}\text { ( ) } & \text { good } \\
\text { () not so good } \\
\text { ( ) } \text { confusing } \\
\text { ( ) non existent }\end{array}$ & $\begin{array}{lll}\text { ( ) } & \text { good } \\
\text { () } & \text { not so good } \\
\text { ( ) } \text { confusing } \\
\text { ( ) } & \text { non existent }\end{array}$ \\
\hline
\end{tabular}

6. If you used bus or subway, how was the

\begin{tabular}{|c|c|c|c|c|c|}
\hline \multicolumn{2}{|c|}{ SIGNALING: } & \multicolumn{2}{|c|}{ EFFICIENCY: } & \multicolumn{2}{|c|}{ COMFORT: } \\
\hline & Subway & Bus & Subway & Bus & Subway \\
\hline $\begin{array}{l}\text { () good } \\
\text { () not so good } \\
\text { () confusing } \\
\text { () nonexstent }\end{array}$ & $\begin{array}{l}\text { () good } \\
\text { () not so good } \\
\text { () confusing } \\
\text { () non existent }\end{array}$ & $\begin{array}{l}\text { () good } \\
\text { () not so good } \\
\text { () confusing } \\
\text { () non existert }\end{array}$ & $\begin{array}{l}\text { () good } \\
\text { () not so good } \\
\text { () confusing } \\
\text { () non existent }\end{array}$ & $\begin{array}{l}\text { () good } \\
\text { () not so good } \\
\text { () confusing } \\
\text { ( ) nonexistent }\end{array}$ & $\begin{array}{l}\text { () good } \\
\text { () ) not so good } \\
\text { () confusing } \\
\text { () non existent }\end{array}$ \\
\hline
\end{tabular}

